\title{
Modificación de variables productivas por inclusión del "poroto caupí" (Vigna unguiculata) en la alimentación de cerdos
}

\author{
Picot, J.A.'; Koslowski, H.A., ${ }^{1,3}$; Slanac, A.L. ${ }^{2,3}$; Sánchez, S. ${ }^{1}$ de Asís, A.N. ${ }^{2,3}$ \\ Cátedras de Bioestadística ${ }^{1}$, Fisiología ${ }^{2}$ y Nutrición y Alimentación ${ }^{3}$, Facultad de Ciencias Veterinarias, \\ UNNE, Sargento Cabral 2139, Corrientes (3400), Argentina. Tel. 03794-425753 (interno 139). \\ E-mail: japicot@gmail.com
}

\begin{abstract}
Resumen
Picot, J.A.; Koslowski, H.A.; Slanac, A.L.; Sánchez, S.; de Asís, A.N.: Modificación de variables productivas por inclusión del "poroto caupi" (Vigna unguiculata) en la alimentación de cerdos. Rev. vet. 26: 1, 49-53, 2015. Es recomendable que la alimentación animal incluya ingredientes obtenidos en las propias regiones donde se realiza la explotación. En el nordeste argentino existe la posibilidad de usar el poroto caupí (Vigna unguiculata) como recurso proteico. El objetivo del trabajo fue verificar la conveniencia de utilizarlo a fin de sustituir en diferentes proporciones al expeller de soja en la dieta de cerdos en crecimiento, midiendo parámetros de desempeño productivo. El ensayo, diseñado para bloques completamente aleatorizados, tuvo una duración de 30 días: 9 días de adaptación y 21 días de medición. La experiencia incluyó 12 animales y 3 dietas: T1, dieta base (DB) preparada con maíz molido (66\%) más expeller de soja (29\%), T2 y T3: DB a las cuales se les reemplazó el 50 y el 75\% del expeller de soja por caupí respectivamente. Del análisis estadístico realizado con el software InfoStat surgió que entre T1, T2 y T3 no hubo diferencias significativas ( $>00,05)$ para la ganancia diaria de peso $(0,25 ; 0,25$ y $0,28 \mathrm{~kg} /$ día respectivamente), consumo diario de alimento $(1,06 ; 0,99$ y $1,00 \mathrm{~kg}$ de materia seca/día) ni conversión alimenticia $(4,21 ; 3,44$ y 4,64 kg). Ello permite concluir que la inclusión de "poroto caupí" en distintos niveles de sustitución del expeller de soja, es una opción viable para la alimentación de cerdos en crecimiento.
\end{abstract}

Palabras clave: cerdo, alimentos alternativos, proteína, parámetros productivos.

\begin{abstract}
Picot, J.A.; Koslowski, H.A.; Slanac, A.L.; Sánchez, S.; de Asís, A.N.: Modification of productive variables for inclusion of "cowpea bean" (Vigna unguiculata) in the feeding of pigs. Rev. vet. 26: 1, 49-53, 2015. It is recommended that for animal feeding the ingredients in the diet should be obtained in the same region of the exploitation. In northeastern Argentina it is possible to use "cowpea beans" (Vigna unguiculata) as a protein resource. The objective of this trial was to verify the suitability of "cowpea beans" to replace expeller soybean in different proportions in the diet of growing pigs, measuring parameters of productive performance. For the trial a totally randomized blocks design was used. It lasted 30 days: 9 days for adaptation and 21 days for measurements. The experience included 12 animals and 3 diets; T1: basal diet (BD) made with ground corn (66\%) and soybean expeller (29\%), T2 and T3: BD to which $50 \%$ and $75 \%$ of soybean expeller were replaced by "cowpea beans", respectively. Statistical analysis was performed with the InfoStat software. The analysis showed that among T1, T2 and T3 treatments there were not significant differences $(\mathrm{p}>0.05)$ for the daily weight gain $(0.25 ; 0.25$ and $0.28 \mathrm{~kg} /$ day respectively), daily food intake (1.06; 0.99 and $1.00 \mathrm{~kg} \mathrm{DM} /$ day) neither nutritious conversion $(4.21 ; 3.44$ and $4.64 \mathrm{~kg})$. This allows us to conclude that the use of "cowpea beans" at different levels of substitution of soybean expeller is a viable option for growing pigs.
\end{abstract}

Key words: pig, alternative food, protein, productive parameters. 


\section{INTRODUCCIÓN}

Desde que la cría de cerdos se inició en nuestro país, su localización coincide con la distribución de los cereales de cosecha gruesa. Este hecho se debe a que la alimentación del cerdo en Argentina tiene como base los granos de maíz, sorgo y soja. Estos cultivos también son empleados en la alimentación humana, lo que determina una importante competencia e influye marcadamente en la fluctuación de los precios de dichos productos ${ }^{21}$.

La Organización de las Naciones Unidas para la Agricultura -FAO- recomienda que en la alimentación animal los ingredientes de la dieta sean obtenidos en las mismas regiones donde se producen. Una alternativa para promover la sustentabilidad de estos sistemas de subsistencia, es el uso de recursos locales de alta producción de biomasa y energía renovable, con bajos requerimientos de insumos y aplicación de tecnología simple en la elaboración de las dietas, sustituyendo total o parcialmente las materias primas originarias de otras regiones ${ }^{1}$.

La producción de cerdos en la Provincia de Corrientes se realiza por sistemas de crianza a campo o mixto, con baja tecnificación, a resultas de lo cual urge incrementar la productividad del sector y mejorar la calidad del producto sin que las inversiones en infraestructura incidan negativamente en los costos, permitiendo una competencia sostenible en un sistema comercial globalizado ${ }^{10,16}$.

Ciertos recursos forrajeros alternativos presentan limitaciones nutricionales en el contenido de energía, fibra y aminoácidos, capaces de afectar el rendimiento productivo, causando una disminución en la eficiencia de conversión de alimentos e incrementando el costo. No obstante, en situaciones de emergencia y mediante un balance adecuado de nutrientes y un bajo nivel de utilización, tales productos pueden sustituir adecuadamente las tradicionales fuentes de proteína y energía de los alimentos balanceados para cerdos ${ }^{2,4}$. En la zona existen varios forrajes que reúnen estos requisitos, aunque la información sobre su valor nutricional en monogástricos es aún escasa ${ }^{6}$.

Una fuente alternativa de proteínas para la alimentación de cerdos podría residir en los granos de los porotos del género Vigna, entre los cuales existe en la zona el caupí (Vigna unguiculata), que posee las características ideales para reemplazar parcialmente la soja en la dieta de cerdos y aves ${ }^{7}$.

El caupí (vocablo derivado del inglés "cowpea") es una leguminosa originaria de África, por lo cual se la cultiva en zonas de clima tropical o sub-tropical. Es una planta autógama que pertenece al género Vigna (nombrado así en honor al médico y botánico italiano Doménico Vigna). El caupí es conocido por varios nombres; así en Argentina se lo denomina poroto arroz, poroto tape, porotito del ojo, poroto señorita; en Brasil se lo conoce como feijão macasar o feijão de corda; en Perú como frijol Castilla; en Cuba y Venezuela como frijol ${ }^{18}$. Posee un elevado contenido de proteínas (18$23 \%$ ) de muy buena calidad nutricional ${ }^{5,19}$.

En Corrientes la porcinocultura tiene un rol complementario en la actividad rural de tipo familiar. Es un sistema productivo que adolece de fragilidad por los elevados costos de producción y la escasa obtención de valor agregado. El gasto en alimentación representa el $70-80 \%$ del costo total de la producción de carne de cerdo, incidiendo negativamente sobre la rentabilidad del sistema. Un factor capaz de incrementar la sostenibilidad es el uso de nutrientes regionales como el caupí, de gran potencial en la alimentación animal ${ }^{18}$. Además de sus ventajas agroecológicas, este poroto posee una proporción de proteína bruta y un perfil de aminoácidos semejante al de la soja ${ }^{9}$, que lo convertiría en una alternativa válida para la alimentación del cerdo. Disminuir el uso de materias primas provenientes de otras provincias, reduciría los costos y permitiría a la mayoría de los porcicultores regionales mantenerse en esta actividad productiva.

El consumo voluntario es probablemente el factor más importante desde el punto de vista pecuario, ya que los demás parámetros como la ganancia de peso y la conversión de alimento dependerán en forma directa del consumo voluntario. Además, debe tenerse en cuenta que el medio interno del animal, incluyendo factores metabólicos, hormonales y gastrointestinales, también despliegan un importante rol en el comportamiento alimentario ${ }^{14}$. En forma complementaria, los cálculos de conversión y de eficiencia alimenticia, expresan la relación de los parámetros mencionados con el consumo, es decir, el comportamiento animal es el resultado del consumo de alimento, y con ello de sus nutrientes, concentración energética, digestibilidad y metabolismo 22,24

El uso de recursos alternativos en nutrición animal no es una propuesta nueva, sin embargo los niveles de inclusión en las dietas para cerdos aún no han sido claramente determinados, pues diferentes pruebas exploratorias sugieren que tiene limitantes, especialmente algunos factores antinutricionales ${ }^{2}$. Un agente antinutricional es una sustancia presente en el alimento que tiene la capacidad de reaccionar o interferir con un nutrimento, disminuyendo su biodisponibilidad y aceptabilidad organoléptica, así como -a largo plazo- producir tratornos fisiológicos y/o anatómicos ${ }^{27}$. El caupí contiene inhibidores de tripsina capaces de interferir la digestión de proteínas, así como fitatos que disminuyen la biodisponibilidad de minerales e inhiben enzimas proteolíticas y amilolíticas. También contiene cianuro de hidrógeno, hemaglutininas y taninos. Existen tratamientos térmicos que mejoran la calidad nutricional de este poroto ${ }^{26}$.

Los fundamentos señalados precedentemente conducen a la búsqueda de fuentes alternativas de proteína de producción local, con el propósito de sustituir al máximo posible el porcentaje de inclusión de soja y así disminuir costos de producción y brindar sostenibilidad a la porcinocultura regional ${ }^{21}$. El objetivo del 
trabajo fue determinar ganancia de peso, consumo de alimento y tasa de conversión, en cerdos en crecimiento alimentados con una dieta cuya fuente de proteína estuvo constituida por distintos niveles de poroto caupí sustituyendo a la soja.

\section{MATERIAL Y MÉTODOS}

Los ensayos se realizaron en el Módulo de Experimentación de Cerdos de la Facultad de Ciencias Veterinarias, UNNE, Corrientes. Se evaluaron dos dietas experimentales conteniendo distintos niveles de caupi y una dieta base carente de dicho poroto, con alto contenido de soja. El caupí se libró a consumo previo tratamiento térmico para minimizar su efecto antinutricional $\left(120^{\circ} \mathrm{C} \text { de calor seco durante } 15 \mathrm{~min}\right)^{26}$.

El la Tabla 1 se describen los ingredientes de cada una de las tres dietas: la dieta base (DB) exenta de cau$p i$, con alto contenido de expeller de soja (29\%) y las dietas restantes conteniendo caupi en porcentajes del 50 y $75 \%$ sustituyendo las respectivas proporciones del expeller de soja. Las dietas fueron formuladas a partir de las necesidades proteicas de la categoría de cerdos utilizada ${ }^{15}$. En la Tabla 2 se detallan los componentes nutricionales de las dietas ofrecidas durante el ensayo.

Para el trabajo se utilizaron 12 animales, 9 machos y 3 hembras, provenientes de dos lechigadas de

Tabla 1. Ingredientes de las dietas.

\begin{tabular}{lccc}
\hline ingrediente (\%MS) & dieta base & dieta 50\% & dieta 75\% \\
\hline soja (expeller) \% & 29 & 18 & 11 \\
caupi $\%$ & 0 & 18 & 33 \\
maíz (molido) \% & 66 & 59 & 51 \\
núcleo* \% & 5 & 5 & 5 \\
total \% & 100 & 100 & 100 \\
\hline
\end{tabular}

MS: materia seca, dieta $50 \%$ : dieta con $50 \%$ de soja y $50 \%$ de caupí, dieta $75 \%$ : dieta con $25 \%$ de soja y $75 \%$ de caupí, *Mixtural Premezcla Viatmínico Mineral (Provimi®).

Tabla 2. Composición de las dietas.

\begin{tabular}{lccc}
\hline componentes & dieta base & dieta $50 \%$ & dieta $75 \%$ \\
\hline materia seca \% & 89,14 & 87,86 & 85,11 \\
proteína bruta \% & 24,01 & 21,69 & 20,92 \\
extracto etéreo \% & 3,36 & 3,38 & 2,71 \\
fibra bruta \% & 4,21 & 3,81 & 4,02 \\
ED Mcal $/ \mathrm{kg}$ & 3,77 & 3,78 & 3,79 \\
\hline
\end{tabular}

ED: energía digerible. Análisis realizado en laboratorios de la Cátedra de Química Agrícola, Fac.Cs.Agrarias-UNNE.

Tabla 3. Estadísticas descriptivas de las variables muestrales.

\begin{tabular}{lccccc}
\hline variable & DB & $\begin{array}{c}\text { dieta } \\
50 \%\end{array}$ & $\begin{array}{c}\text { dieta } \\
75 \%\end{array}$ & EE & $\mathrm{p}$ \\
\hline ganancia (kg/día) & 0,25 & 0,25 & 0,28 & 0,03 & 0,6575 \\
consumo (kgMS/día) & 1,06 & 0,99 & 1,00 & 0,11 & 0,8743 \\
conversión (kg) & 4,21 & 3,44 & 4,64 & 0,56 & 0,3249 \\
\hline
\end{tabular}

DB: dieta base, EE: error estándar, p: significancia. un mismo padrillo de raza Pietrain, y de dos madres Landrace, por lo que se lograron similares características genotípicas. Los cerdos, clínicamente sanos, fueron vacunados y desparasitados acorde al manejo sanitario habitual de los establecimientos de la región. Las unidades experimentales para los ensayos pesaron $16 \pm 3 \mathrm{~kg}$ y fueron alojados en jaulas individuales de $2,5 \mathrm{~m}^{2}$.

Las variables cuantitativas consideradas fueron: ganancia diaria de peso ( $\mathrm{kg} / \mathrm{día})$, consumo diario de alimento (gramos de materia seca/día) y conversión alimenticia $(\mathrm{kg})$, con un diseño en bloques completamente aleatorizados con 4 repeticiones. Se estipularon lapsos de 9 días de adaptación, tanto a las dietas como a la metodología de trabajo (durante este período las dietas a probar fueron ofrecidas de forma progresiva) y 21 días de experimentación, durante los cuales se realizaron las mediciones.

Las dietas se brindaron en dos comidas diarias, 08:30 y 16:30 horas, la medición de consumo se realizó por diferencia entre el peso del alimento ofertado y el sobrante, controlando durante todo el período de medición, que estos no fueran menores al $10 \%$ de la oferta para considerar que las raciones (tratamientos a evaluar) fueron suministradas ad libitum. Los animales se controlaron diariamente, observando su estado general, pelaje y consistencia de la materia fecal. La evolución del peso corporal se evaluó pesando cada animal sin previo ayuno, con una balanza digital con capacidad de hasta $200 \mathrm{~kg}$; los pesajes se efectuaron durante los días 1,14 y 21 del período de medición. Para el ensayo se utilizó un diseño en bloques completamente aleatorizado ${ }^{25}$, cuyo modelo lineal aditivo es:

$$
\mathrm{Y}_{\mathrm{ij}}=\mu+\tau_{\mathrm{i}}+\beta_{\mathrm{j}}+\varepsilon_{\mathrm{ij}}
$$

$\mathrm{Y}_{\mathrm{ij}}=$ respuesta que en el bloque $j$-ésimo recibe el tratamiento $i$-ésimo, $\mu=$ media general, $\tau_{\mathrm{i}}=$ efecto del i-ésimo tratamiento, $\beta_{\mathrm{j}}=$ efecto del j-ésimo bloque y $\varepsilon_{\mathrm{ij}}=$ error aleatorio.

En todos los casos se comprobaron los supuestos de normalidad (Wilk-Shaphiro), homogeneidad de la variancia (Levene) y no-aditividad de los efectos de bloques/tratamientos. Por la característica de la prueba siempre se cumplió con el supuesto de independencia. Para el análisis de varianza, la hipótesis nula $\left(\mathrm{H}_{0}\right)$ se rechazó con un nivel de $\alpha$ del 5\%. Software utilizado: InfoStat.

\section{RESULTADOS Y DISCUSIÓN}

Los cerdos asignados a las distintas dietas no revelaron cambios indeseables de su estado general ni consistencia anómala de la material fecal.

La Figura 1 muestra la evolución del peso de los animales durante el ensayo. La Tabla 3 exhibe la ganancia diaria de peso, el consumo diario de alimento y la conversión alimenticia, datos que en ningún caso fueron significativamente diferentes entre sí $(p>0,05)$, 


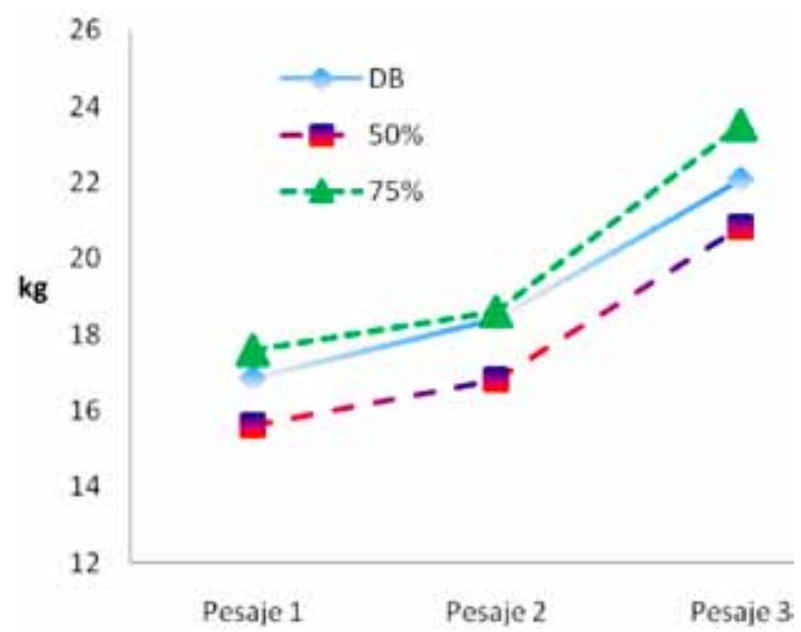

Figura 1. Evolución del peso vivo durante el ensayo. DB: dieta base; $50 \%$ : dieta con $50 \%$ de soja y $50 \%$ de caupi; $75 \%$ : dieta con $25 \%$ de soja y $75 \%$ de caupí.

para los dos niveles de sustitución parcial de proteína de soja por caupí.

La "dieta $75 \%$ " (25\% de soja y $75 \%$ de caupí) registró una mejor performance en ganancia diaria de peso $(0,28 \mathrm{~kg} /$ día), en coincidencia con un mayor consumo de alimento (1,00 kg de MS/día). Los animales asignados a esta dieta necesitaron en promedio menor cantidad de alimento $(4,64 \mathrm{~kg} / \mathrm{kg}$ de peso vivo ganado). Los cerdos que recibieron la dieta base (DB) fueron los que necesitaron mayor cantidad de alimento por kilogramo de peso vivo ganado.

En otros ensayos, al incluir grano de caupí crudo y cocido en cantidades crecientes hasta el $20 \%$ en la dieta de pollos de engorde, no se registraron diferencias en el consumo de alimento ${ }^{11}$. Respuestas similares se observaron en ratas que recibieron dietas con 20,40,60, 80 y $100 \%$ de inclusión de caupí crudo en reemplazo del expeller de soja, afectándose solamente las variables de comportamiento productivo a partir del $80 \%$ de inclusión, concluyéndose que se puede llegar hasta el $60 \%$ de reemplazo ${ }^{3}$.

Al alimentar cerdos de $11 \mathrm{~kg}$ de peso vivo con otro recurso del género Vigna, poroto "mungo" cocido (Vigna radiata) como fuente de sustitución del $40 \%$ de soja, se registraron disminuciones del consumo diario de alimento, atribuyéndose este comportamiento a la presencia de taninos ${ }^{13,20}$.

Un estudio en pollos de engorde consumiendo harina de granos de caupí crudo, con inclusiones del 10, 15 y $20 \%$ en las dietas (llegando a aportar $30 \%$ de la proteína bruta, equivalente a la sustitución del $60 \%$ de la soja), no se encontraron diferencias significativas entre los tratamientos para las variables peso vivo y conversión. De acuerdo a la respuesta biológica obtenida, los investigadores concluyeron que esta fuente proteica alternativa puede emplearse eficiente y competitivamente con los niveles de inclusión empleados hasta el momento ${ }^{12}$.
Otros autores reportaron que al alimentar cerdos en crecimiento con harina de hojas de caupí, los parámetros productivos ganancia de peso, consumo $\mathrm{y}$ conversión alimenticia tuvieron valores inferiores a los esperados teóricamente ${ }^{23}$, en coincidencia con los resultados obtenidos en el presente trabajo.

Probando dietas con un $30 \%$ de sustitución de proteína de soja por poroto "mungo" (Vigna radiata), no se encontraron diferencias significativas en las variables de desempeño productivo, consumo de alimento, peso corporal, conversión alimenticia ${ }^{8,17}$. Con la incorporación de harina integral de "matarratón" (Gliricidia sepium) en niveles del $30-40 \%$ en reemplazo de la fuente proteica (soja) en la alimentación de cerdos, se lograron diferencias significativas para las variables productivas $^{28}$.

En conclusión, surge que las variables de desempeño productivo analizadas en el presente trabajo no variaron significativamente según las dietas ensayadas, por lo cual se induce que la fuente proteica tradicional (expeller de soja) puede ser parcialmente sustituida por un recurso alternativo como el poroto caupí en la alimentación de cerdos en crecimiento, práctica que aumentará el valor agregado y favorecerá al pequeño productor rural de la región.

\section{REFERENCIAS}

1. Abeledo C, Santana I, Pérez I, Brache F. 2004. Rasgos de comportamiento y canal de cerdos criollos y CC21 alimentados con palmiche como única fuente de energía. Rev Comp Prod Porc 11: 96-104.

2. Acurero GA, Alvarado LR, Pérez SA, Álvarez RG, Cuaimara MR. 1981. La harina de batata (Ipomoea batata) como fuente energética en raciones para cerdos en crecimiento. Rev Ciencias Vet 10: 1407-1414.

3. Aguirre LA, Savón L, Santos Y, Dihigo LE. 2002. Protein metabolism and productive performance of rats consuming raw cowpea (Vigna unguiculata) grain meal to substitute commercial soybean cake. Cuban J Agric Sci 36: 159-164.

4. Alvarado LR, Álvarez RG, Acurero GA. 1977. Utilización de la harina de batata (Ipomoea batata) en la alimentación del cerdo. Rev Cs Vet Maracay 6: 955.

5. Avanza MV, Añón MC. 2008. Aislamiento y caracterización fisicoquímica y funcional de proteínas de caupí (Vigna unguiculata). Actas de Reunión de Comunicaciones Cientificas y Tecnológicas 2008 (SGCyT-UNNE) $\mathrm{N}^{\mathrm{o}}$ E-305. http://www.unne.edu.ar/unnevieja/investigacion/ com2008/exactas.php

6. Belmar CR. 1998. Recursos no convencionales en la alimentación de animales no rumiantes. En: Metodologías de investigación pecuaria en sistemas de producción de pequeños productores (Ed. Centro de Investigación Agrícola Tropical), Santa Cruz, Bolivia, p. 51-67.

7. Castro M, Díaz J, Castañeda J, Báez L, Díaz MF, Ly J, Cino DM. 2002. Una alternativa nacional como fuente de proteína para cerdos en crecimiento: Vigna unguiculata vc. INIFAT-93. Rev Cub Ciencia Agric 36: 347-350. 
8. Echeverría RW, Sarmiento FL, Santos RR, Kú VJ. 2005. Nutrient digestibility in Pelon mexicano pigs fed graded levels of cowpea meal (Vigna unguiculata). Rev Comp Prod Porc 12: 39-42.

9. Food and Agriculture Organization (FAO/WHO). 1991. Protein quality evaluation. FAO Food and Nutrition Paper $\mathrm{N}^{\mathrm{o}}$ 51, Roma, $66 \mathrm{p}$.

10. Hernández ZJ, Pérez R, Silva SE, Hernández JA, González S. 2011. Los traspatios multifuncionales y sustentables. Informe Red Conbiand, Univ Autón Chiapas (México), p. 71-97.

11. Jabib L, Barrios P, Vega A. 2002. Evaluación del fríjol caupí (Vigna unguiculata) como ingrediente proteico en dietas para pollos de asadero. Rev Med Vet Zoot (Córdoba) 7: 162-167.

12. Lon-Wo E, Rodriguez B, Dieppa O. 2001. Evaluación económica y biológica de harina de vigna (Vigna unguiculata) en dietas isoproteicas para pollos de engorde. Rev Cub Ciencia Agríc 35: 25-28.

13. López BA, Domínguez M, Díaz OA. 1996. Obtención y empleo de la harina de frijol verde. Anales Jornada Científico-Técnica y Productiva sobre el cultivo de la Vigna en Cuba, La Habana, p. 17.

14. Ly J. 1993. Fisiología digestiva del cerdo. Anales II Curso sobre biometría, fisiología, nutrición y alimentación de cerdos, Maracay (Venezuela), p. 125.

15. National Research Council (NRC). 2001. Nutrient Requeriment of Swine, Ed. National Academy of Sciencies, Washington, $68 \mathrm{p}$.

16. Perezgrovas R, Rodríguez G, Zaragoza L. 2011. El traspatio iberoamericano. En: $X V$ Anuario de Estudios Indigenas (Ed. Instituto de Estudios Indígenas), Chiapas (México), p. 294.

17. Perez-Rubio MR. 2011. Evaluación de la composición nutricional y digestibilidad aparente e ileal en porcinos del frijol mungo (Vigna radiata o Phaseolusaureus) con y sin tratamiento térmico. Tesis de Maestría en Cs. Agrarias, Univ. Nac.de Colombia,http://www.bdigital.unal.edu. co/7179/1/mariadelrocioperezrubio.2012.pdf
18. Peters M, Franco LH, Schmidt A, Hincapié B. 2011. Especies forrajeras multipropósito: opciones para productores del trópico americano, Ed. Centro Internacional de Agricultura Tropical (CIAT-Public.374), Cali, Colombia, $212 \mathrm{p}$.

19. Peyrano F, Chaves MG, Acevedo BA, Avanza MV. 2012. Composición nutricional y antinutricional de caupí variedad California Black cultivado en el nordeste argentino. Actas XVIII Reunión Comunic Cientif \& Tecn SGCYT-UN$N E$, P.I. 141/07. http://www.unne.edu.ar/unnevieja/investigacion/com2012/CE-094.pdf

20. Piloto JL, Mederos CM, Aleman E, Juncal J. 2001. Utilización de la vigna radiata en la alimentación de cerdos en crecimiento/ceba. Rev Comp Prod Porc 8: 14-19.

21. Revidatti MA. 2009. Caracterización de cerdos criollos del nordeste argentino. Tesis, Univ. de Córdoba, España. https://es.scribd.com/doc/39553903/Tesis-Maria-AntoniaRevidatti

22. Secretaría de Agricultura, Ganadería, Pesca y Afines (Argentina). 2001. Análisis FODA del sector porcino nacional. www.sagpya.mecon.gov.ar/0-1/porcinos

23. Sarria P, Rivera LF, Araujo R, Peters M. 2010. Follaje de caupí (Vigna unguiculata) como fuente de proteína para cerdos en crecimiento. Rev Comp Prod Porc 17: 229233.

24. Shimada MA. 2005. Nutrición Animal, Ed. Trillas, México, $388 \mathrm{p}$.

25. Steel R, Torrie J. 1993. Bioestadística principios y procedimientos, Ed. McGraw Hill, México, 622 p.

26. Udensi EA, Ekwu FC, Isinguzo JN. 2007. Antinutrient factors of vegetable cowpea (sesquipedalis) seeds during thermal processing. Pakistan J Nutr 6: 194-197.

27. Valle P, Florentino BA. 2000. Toxicología de Alimentos, Ed. Instituto Nacional de Salud Pública, México, 261 p.

28. Vásquez P, Rosso L. 1996. Evaluación de la harina de matarratón (Gliricidia sepium) sobre la ganancia de peso de cerdos en crecimiento. Zoot Trop (Venezuela), 14: 99-104. 